\title{
The Effect of Information Booklets on Family Members' Satisfaction with Decision Making in an Intensive Care Unit of Malaysia
}

\author{
Hamidah Othman ${ }^{1 *}$, Pathmawathi Subramanian ${ }^{2}$, Noor Azizah Mohd Ali ${ }^{3}$, Haszalina Hassan ${ }^{4}$, Mainul Haque ${ }^{5}$ \\ 'School of Nursing Science, Faculty of Medicine, Universiti Sultan Zainal Abidin (UniSZA), Campus Gong Badak, 21300 Kuala Terengganu, MALAYSIA. \\ 2Department of Nursing Science, Faculty of Medicine, University of Malaya (UM), 50603 Kuala Lumpur, MALAYSIA. \\ ${ }^{3}$ Department of Critical Care Nursing, Kulliyyah of Nursing, International Islamic University Malaysia (IIUM), 25200, Kuantan, Pahang, MALAYSIA. \\ ${ }^{4}$ School of Nursing Science, Faculty of Medicine, Universiti Sultan Zainal Abidin (UniSZA), 21300 Kuala Terengganu, MALAYSIA. \\ SProfessor of the Unit of Pharmacology, Faculty of Medicine, Universiti Sultan Zainal Abidin, Medical Campus, Jalan Sultan Mahmud, 20400 Kuala Terengganu, \\ Terengganu, MALAYSIA.
}

\begin{abstract}
Background: To test the effect of information booklets on family members' satisfaction with decision-making around the care of critically ill patients in an intensive care unit. Design: Quasi-experiment with non-randomized study groups, using a pre and post-test design was used to test the effectiveness of the information booklet. Setting: The study was conducted in a medical center in Malaysia. Subjects: 84 family members of critically-ill patients were conveniently assigned to an intervention group and a control group. Intervention: On admission day after consented, completed pre test questionnaires. The intervention group received information booklet and will be explain between 20-30 minutes; control group, received routine information if any. Day-2: reinforcement on information about 10-20 minutes for intervention group only. Day-3: completion of the post-test questionnaire by both groups. Main outcome measures: The Family Satisfaction-Intensive Care Unit (FS-ICU) and Quality of Communication (QOC) instrument were used to measure families' satisfaction level. Results: There are significant differences in Family Satisfaction between the intervention and control groups. There was an increase in satisfaction across the pre- and post-test mean values, $54.05(S D=10.23)$ and $71.1(S D=19.10)$, respectively; a significant increase in family satisfaction for the intervention group who received the information booklets. Conclusion: The study findings confirm that the information booklets results in a substantial increase in family satisfaction regarding decision-making for patients' care.
\end{abstract}

Key words: Decision making, Family satisfaction, Information need, Intensive care unit, Structured Communication.

\section{PICTORIAL ABSTRACT}

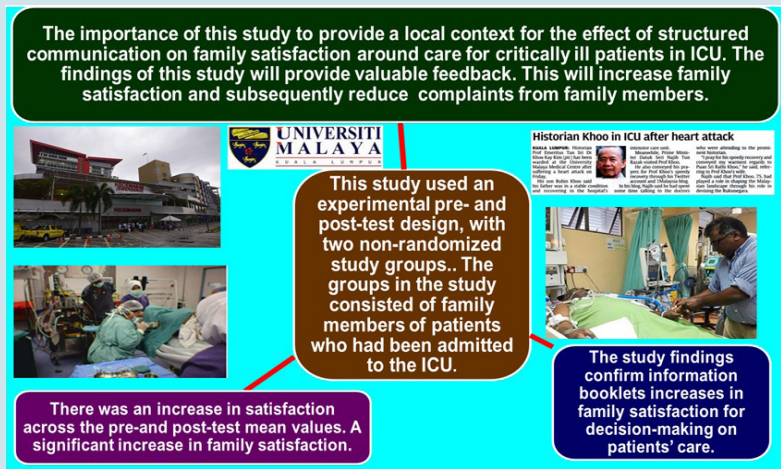

Correspondence :

Hamidah Othman,

School of Nursing Science, Faculty of Medicine, Universiti Sultan Zainal Abidin

(UniSZA), Campus Gong Badak, 21300 Kuala Terengganu, MALAYSIA.

Tel no: +6096688562; H/P no: +60132036156

E-mail: hamidah@unisza.edu.my; hamidahothman78@gmail.com

DOI: 10.5530/jyp.2016.2.13

\section{INTRODUCTION}

Admission to an intensive care unit (ICU) is often a situational crisis for patients' family members. Family members are initially shocked, confused and struggle to understand what has happened. Families of critically ill patients are not just visitors, but they are caregivers, decisionmakers and people who are dealing with the hour-by-hour psychological stress of uncertainty. ${ }^{1-3}$ Patients who are critically ill normally unable to decide their own decisions due to illness and delirium; thus, family members have a right to be involved in daily decision-making and patient care in the ICU) ${ }^{4-6} \mathrm{ICU}$ treatment requires urgent decisions to be made under tremendous pressure, placing a lot of stress on patients' family members. ${ }^{7-9}$ Seeing patients in critical condition or experiencing terminal illness can be a very scary experience for family members. ${ }^{10,11}$ Thus, patients' family members are also personally affected by their experience with critical care. ${ }^{1,12-16}$

Misunderstandings and misconceptions are not uncommon during the process of communication and can result in confusion, frustration, and anger. ${ }^{17,18}$ The environment of ICU contributes difficulty in learning process towards the medical staff in providing information needs for family members to understand complex issues well enough to make informed decisions. ${ }^{19-21}$ Family members of ICU patients may be at increased risk of suffering psychological effects and anxiety due to the stress of having to make a decision about the patient's care. ${ }^{22,23}$ Thus, having clear lines of communication between ICU staff and family members will increase family members' satisfaction with decisions made regarding the care of the patient. Satisfaction has typically been conceptualized as a global evaluation. ${ }^{24,25}$ ICUs have faced several complaints about the lack of communication in the process of decision-making about care..$^{26,27}$ Therefore, research is needed to examine the components of satisfaction and address the contradictions surrounding the factors.

A multiple of patient populations were not being well documented in research on information needs. The nurses' and family members' perspectives regarding this topic are still lacking in Malaysia. Previous international studies have focused on the ICU setting which is, debated, mostly on problematic settings for communication between care providers and families. ${ }^{14,27-29}$ According to another research report full comprehension of information helps the family cope with the psychological stress associated with ICU admission. ${ }^{30}$ The importance of this 
study is that it provided a local context for the effect of structured communication on family satisfaction around care for critically ill patients in ICU. It is also hoped that, the findings from this study will provide valuable feedback and input to hospitals regarding strategic planning in the provision of structured communication in the ICU or training of nurses to enhance delivery of information. This will increase family satisfaction and subsequently reduce complaints from family members.

\section{MATERIALS AND METHODS}

Design: This study used an experimental pre- and post-test design, with two non-randomized study groups. The study was conducted to evaluate family satisfaction with ICU of University Malaya Medical Centre, Kuala Lumpur, Malaysia and the effect of information booklets between two groups: the intervention and control groups. The groups in the study consisted of family members of patients who had been admitted to the ICU. Participants: This study involved the groups consisted of family members of patients who had been admitted to ICU. The convenience sampling were being carried out in order to recruit sufficient numbers of patients to intervention and control groups at the same period of time. The intervention group received the information booklets and control group were received usual care. Based on previous studies that intended to measure the effectiveness of structured communication program for family members revealed Standard Deviation of overall satisfaction within experimental and control group of $+/-2.99$ and difference means were $1.93 .{ }^{31}$ The calculation was done using Power \& Sample size software; there are 84 subjects in total are required for this study with 42 subjects in intervention and control group respectively. Ethical Considerations: Ethical approval was obtained from the Medical Ethical Committee (UMMC), University of Malaya, Malaysia. All the participants were given a copy of the information sheet and consent for the study was obtained. Instruments: The instrument used in this study was a selfreporting scale designed to assess family satisfaction with care and decision-making in the ICU. The Family Satisfaction in the Intensive Care Unit (FS-ICU) survey version 11 was used in this study. ${ }^{32}$ The statements are rated on a scale with responses ranging from 1 to 5 (1=very dissatisfied and $5=$ very satisfied). This instrument was divided into 2 subscales: Part 1, which was family satisfaction with care; and Part 2, which was family satisfaction with decision-making. Overall satisfaction was divided into 2 sections: 'care' (including patient care, family care, professional care and ICU environment) and information/decisionmaking' (covering information needs and family needs). Intervention: The intervention group received an information booklet while the control group received usual care. The data were collected from October 2012 to January 2013. The data collection process was divided into two phases to prevent contamination between the control and experimental groups. In the first phase, data were collected from the control group first. Data collection for the control group continued until all pre-test and post-test data were obtained from the 42 family members of patients admitted to the ICU. After completion of all post-test by the control group, the intervention phase of the study was initiated. Data collection from the intervention group was carried out until the pre-test and posttest data had been obtained from all 42 family members in the group. For both groups, pre-test was carried out approximately 24-h after admission of the patient in the ICU. For the experimental group, the intervention began immediately after the pre-test. The control group received only the usual information and care. For both groups, the post-test was carried out on the third day following admission. If a patient died, the family members were removed from the study because it was thought that carrying out the post-test within the required time frame would cause more stress for grieving family members and that the loss of a loved one might have a confounding effect. Data Analysis: Data was analyzed using Social Package Statistical Software (SPSS) version 21 (IBM Crop. Released 2010). Normality test was done and descriptive and inferential statistic was used in this study.

\section{RESULTS}

All descriptive data results are shown in tabular form by providing mean, standard deviation (SD), frequency and percentage. To examine the total FS-ICU scores, the researcher used a two-way, repeated measures analysis to compare the mean pre-test and post-test scores.

\section{Demographic Characteristics of Participants}

The demographic data of the family members are presented in Table 1. The gender of both groups was predominantly male. The mean age of the family members was $41.37 \pm 9.02$, with the youngest being 22 years old and the oldest 58 years old.

\section{Satisfaction among Family Members in ICU}

Table 2 shows the mean pre-test and post-test FS-ICU Total (overall) scores for both intervention and control groups. The pre-test mean score for the intervention group was $54.05 \pm 10.23$ and the post-test mean was $71.1 \pm 19.10$. There was an increase in satisfaction across the pre- and post-test period in the intervention group, $33.9 \pm 8.28$ and $45.07 \pm 11.19$, respectively. This was in contrast with the control group, in which there was no difference in the FS-ICU Care scores between the pre- and post-test period, $33.9 \pm 8.28$ and $33.5 \pm 9.73$, respectively. The FS-ICU Decision-Making pre-test score for the intervention group was $22.7 \pm 4.09$ while the post-test score was $29.6 \pm 9.46$. Meanwhile, the control group reported pre- and post-test scores of $22.7 \pm 4.09$ and $21.7 \pm 5.43$, respectively, showing a decrease in satisfaction.

\section{Effect of the Information Booklet on Family Members' Satisfaction}

The repeated measures analysis of variance (ANOVA) was used to compare the mean pre-test and post-test scores for the two groups (Table 3 ). Wilk's lambda was 0.863 , p-value 0.001 (0.001), effect size 0.137 (>0.14) and power $94.3 \%(>80 \%)$. There is a difference in the mean values between the 2 time periods. The mean FS-ICU: Total score before intervention was $54.05 \pm 10.23$ ), with a range of 31 to 81 , and the mean FS-ICU: Total after intervention was $71.10 \pm 19.15$ ), with a range of 36 to 107 . This indicates that the structured communication program is effective for family members.

\section{Quality of Communication}

Table 4 shows the initial mean score for the intervention group, $31.79 \pm$ 8.81 , and the post-test mean score of $37.52 \pm 6.28$. Descriptively, this indicates that there was an increase in the quality of communication across the pre- and post-test period in the intervention group. Meanwhile, the control group reported an initial mean score of $30.07 \pm 8.32$ for the quality of communication and post-test score of $28.31 \pm 6.03$. Descriptively, this indicates that there was a reduction in the quality of communication pre- and post-test in the control group.

\section{DISCUSSION}

\section{Satisfaction among Family Member in ICU}

The finding of family satisfaction with ICU care was shown to have increased significantly from pre-test to post-test, with the highest level of satisfaction in the intervention group similar to the study. ${ }^{33}$ Previous research examined family satisfaction with care provided to critically ill patients and their families in six ICUs across Canada. ${ }^{34}$ This study found 
Table 1: Demographic characteristics of family members in both groups ( $N=84)$

\begin{tabular}{|c|c|c|c|c|c|c|c|c|c|}
\hline & \multicolumn{2}{|c|}{$\begin{array}{l}\text { Overall } \\
(\mathrm{N}=84)\end{array}$} & \multicolumn{2}{|c|}{$\begin{array}{l}\text { Intervention group } \\
\qquad(n=42)\end{array}$} & \multicolumn{2}{|c|}{$\begin{array}{l}\text { Control group } \\
\qquad(n=42)\end{array}$} & \multirow[t]{2}{*}{$t$} & \multirow[t]{2}{*}{$x^{2}$} & \multirow[t]{2}{*}{$p$-value } \\
\hline & $\begin{array}{l}\text { Mean } \\
(+/-S D)\end{array}$ & $\begin{array}{c}n \\
(\%)\end{array}$ & $\begin{array}{l}\text { Mean } \\
(+/-S D)\end{array}$ & $\begin{array}{l}n \\
(\%)\end{array}$ & Mean (+/-SD) & $\begin{array}{c}n \\
(\%)\end{array}$ & & & \\
\hline \multicolumn{10}{|l|}{ Gender } \\
\hline Male & & 45 (53.6) & & $22(52.4)$ & & $23(54.8)$ & & ${ }^{* *} 0.48$ & 0.83 \\
\hline Female & & $39(46.4)$ & & $20(47.6)$ & & $19(45.2)$ & & & \\
\hline Age & $41.37(9.02)$ & & $42(8.7)$ & & 40.7 (9.39) & & ${ }^{*} 0.79$ & & 0.5 \\
\hline \multicolumn{10}{|l|}{$\begin{array}{l}\text { Relationship with } \\
\text { patient }\end{array}$} \\
\hline Husband & & $23(27.4)$ & & $9(21.4)$ & & $14(33.3)$ & & & \\
\hline Wife & & $21(25)$ & & $7(16.7)$ & & $14(33.3)$ & & & \\
\hline Father & & $4(4.8)$ & & $3(7.1)$ & & $1(2.4)$ & & & \\
\hline Mother & & $6(7.1)$ & & $3(7.1)$ & & $3(7.1)$ & & & \\
\hline Brother & & $6(7.1)$ & & $3(7.1)$ & & $3(7.1)$ & & & \\
\hline Son & & $13(15.5)$ & & $7(16.7)$ & & $6(14.3)$ & & & \\
\hline Daughter & & $11(13.1)$ & & $10(23.8)$ & & $1(2.4)$ & & & \\
\hline \multicolumn{10}{|l|}{ Experience } \\
\hline Yes & & $48(57.1)$ & & $22(52.4)$ & & $26(61.9)$ & & ${ }^{* *} 0.77$ & 0.37 \\
\hline No & & $36(42.9)$ & & $20(47.6)$ & & $16(38.1)$ & & & \\
\hline \multicolumn{10}{|l|}{ Staying with } \\
\hline Yes & & $51(60.7)$ & & $21(50)$ & & $30(71.4)$ & & $* * 4.21$ & 0.03 \\
\hline No & & $33(39.3)$ & & $21(50)$ & & $12(28.6)$ & & & \\
\hline \multicolumn{10}{|l|}{ Residence } \\
\hline In the city & & $47(56)$ & & $22(52.4)$ & & $25(59.5)$ & & \multirow{2}{*}{${ }^{* *} 0.19$} & \multirow{2}{*}{0.66} \\
\hline Out of town & & $37(44)$ & & $20(47.6)$ & & $17(40.5)$ & & & \\
\hline \multicolumn{10}{|l|}{ Education } \\
\hline Primary & & $34(40.5)$ & & $15(35.7)$ & & $19(45.2)$ & & \multirow{3}{*}{$* * 3.24$} & \multirow{3}{*}{0.35} \\
\hline Secondary & & $31(36.9)$ & & $16(38.1)$ & & $15(35.7)$ & & & \\
\hline Tertiary & & $19(22.6)$ & & $11(26.2)$ & & $8(19.0)$ & & & \\
\hline \multicolumn{10}{|l|}{ Income } \\
\hline Low income & & $18(21.4)$ & & $6(14.3)$ & & $12(28.6)$ & & \multirow{3}{*}{${ }^{* *} 4.42$} & \multirow{3}{*}{0.035} \\
\hline Moderate income & & $56(6.7)$ & & $29(69.0)$ & & $27(64.3)$ & & & \\
\hline High income & & $10(11.9)$ & & $7(16.7)$ & & $3(7.1)$ & & & \\
\hline
\end{tabular}

${ }^{*}=$ Independent $\mathrm{t}$-test. ${ }^{* *}=$ Chi-Square test.

Table 2: Descriptive of the Family Satisfaction-ICU scores for both intervention and control group

\begin{tabular}{|c|c|c|c|c|c|c|c|c|}
\hline & \multicolumn{4}{|c|}{$\begin{array}{l}\text { Intervention group } \\
(n=42)\end{array}$} & \multicolumn{4}{|c|}{$\begin{array}{l}\text { Control group } \\
\qquad(n=42)\end{array}$} \\
\hline & \multicolumn{2}{|c|}{ Pre test } & \multicolumn{2}{|c|}{ Post test } & \multicolumn{2}{|c|}{ Pre test } & \multicolumn{2}{|c|}{ Post test } \\
\hline & Mean & (+/-SD) & Mean & (+/-SD) & Mean & (+/-SD) & Mean & (+/-SD) \\
\hline FS-ICU: Total & 54.05 & $(10.23)$ & 71.1 & $(19.10)$ & 56.62 & $(10.41)$ & 51.86 & $(9.18)$ \\
\hline FS-ICU: Care & 33.9 & $(8.28)$ & 45.07 & $(11.19)$ & 33.9 & $(8.28)$ & 33.5 & $(9.73)$ \\
\hline FS-ICU: Decision Making & 22.7 & $(4.09)$ & 29.6 & $(9.46)$ & 22.7 & $(4.09)$ & 21.7 & $(5.43)$ \\
\hline
\end{tabular}

Table 3: Descriptive of the Family satisfaction-ICU Total scores for both intervention and control group

\begin{tabular}{|c|c|c|c|c|c|c|}
\hline \multirow[b]{2}{*}{ FS-ICU: Total scores } & \multicolumn{2}{|c|}{$\begin{array}{l}\text { Mean scores (SD) } \\
\qquad(\mathrm{N}=84)\end{array}$} & \multirow[t]{2}{*}{$\mathbf{N}$} & \multirow{2}{*}{$\begin{array}{c}\begin{array}{c}\text { Wilks' } \\
\text { Lambda }\end{array} \\
0.863\end{array}$} & \multirow{2}{*}{$\frac{d f}{1}$} & \multirow{2}{*}{$\begin{array}{c}\text { p-value } \\
0.001\end{array}$} \\
\hline & Pre test & Post test & & & & \\
\hline Intervention group & $54.5(10.23)$ & $71.10(19.15)$ & 42 & & & \\
\hline Control group & $56.62(10.41)$ & $51.86(9.18)$ & 42 & & & \\
\hline Total & $55.33(10.34)$ & $61.48(17.79)$ & 84 & & & \\
\hline
\end{tabular}




\begin{tabular}{|c|c|c|c|c|c|c|c|c|}
\hline & \multicolumn{4}{|c|}{$\begin{array}{l}\text { Intervention group } \\
\qquad(n=42)\end{array}$} & \multicolumn{4}{|c|}{$\begin{array}{c}\text { Control group } \\
(n=42)\end{array}$} \\
\hline & \multicolumn{2}{|c|}{ Pre test } & \multicolumn{2}{|c|}{ Post test } & \multicolumn{2}{|c|}{ Pre test } & \multicolumn{2}{|c|}{ Post test } \\
\hline & Mean & (+/-SD) & Mean & $(+/-S D)$ & Mean & $(+/-S D)$ & Mean & (+/-SD) \\
\hline $\begin{array}{c}\text { Quality of } \\
\text { communication }\end{array}$ & 31.79 & $(8.81)$ & 37.52 & $(6.28)$ & 30.07 & $(8.32)$ & 28.31 & $(6.03)$ \\
\hline
\end{tabular}

that higher satisfaction level among family members with the care provided to relatives in the intensive care unit. This study not only focused on satisfaction with care but also on decision-making around care in the ICU. The findings showed significant differences between the mean values in the control group, indicating that the family members were satisfied with decision-making in the ICU. However, another study, which studied the perspectives of the substitute decision-maker, found that most substitute decision-makers for ICU patients preferred to discuss decision-making responsibility with health care providers..$^{35}$ On the other hand, substitute decision-maker satisfied with their decision-making experience because there was good communication and support, enabling them to achieve the effective care for their family member. In order for health care professionals to be able to move from a curative approach to comfort-oriented care, a consensus among all parties involved in the decision-making process must be reached. ${ }^{36}$ The aim of measuring family satisfaction is to introduce this program into a quality improvement initiative and also to increase the quality of care in the ICU setting.

\section{Factor influences the family satisfaction with decision making on care}

The present study highlights several factors that related to satisfaction with care among family member in ICU. The repeated measure analyses indicated that, there was no significant association with the variables of "relationship with the patient", "experience with care patient in ICU", "residence", "educational level" and "income" of family member except the variable "staying with" where family members who live with the patient shown the association with the family satisfaction-ICU score. The similar finding in a study stated that the family members should be near to the patient, thus, they will able to help with care and to know the physical and emotionally comfortable of their family as possible. ${ }^{37}$ That was reported that family members who staying together with the patient were higher satisfaction with care from those who not staying with the patient because they know more about the needs of patients.

\section{The effect of information booklets on family members' satisfaction}

In this study, the family members who received the information booklet had a significant increase in their satisfaction level compared with the group who received the usual information. The effect of using this booklet confirms similar to that of a previous study the importance of including patients and relatives in the process of communication to ensure that their need for information is being met. $^{38}$

\section{Limitation}

This study depended on personalized self-reported data, which might have been influenced by a social desirability bias and lack of cooperation from family members due to the short visiting hours. Almost all family members in the ICU preferred to spend their time with the patient during the visiting hours.

\section{RECOMMENDATION}

Research finding shows, the researchers emphasized on the level of satisfaction among the patient's relative regarding the quality of care should be the main focus. Family members play a major role in the care of patients who have been admitted into the Intensive Care unit and are entitled to know what is the best treatment for their loved ones. These findings suggest that there is a beneficial effect of using information booklets widely in the hospital setting, especially in critical wards such as the intensive care unit. Therefore, nurses can use these study findings to plan orientation sessions for newly-admitted patients in the Critical Care Unit. Furthermore, the use of information booklets can be an evidence-based practice for all nurses and should be included in updating clinical practice guidelines. In the field of nursing education, it is a challenge to produce nurses who are knowledgeable, and skilled. The behavior of nurses must be well-managed from the beginning of the staff member's career. Nursing educators must be firm in providing guidance to students. Failure to follow the rules and adopting practices contrary to nursing principles will be harmful to the patients. Creating an attitude of tolerance and good communication is the way to establish a positive relationship between nursing staff, patients and family members.

\section{CONCLUSION}

In summary, this study has shown increasing levels of family satisfaction among the intervention group with the care and decision-making in the ICU. Satisfaction with care and the quality of communication using an information booklet increased significantly in the intervention group from pre-test to post-test. These findings may indicate that those with the greatest need for information booklets, and who will derive the largest benefit, and relatives who have had no experience with the ICU. Although the findings cannot be generalized, it can be tested using the same program in other units and settings. Even though this program was carried out within a brief period, daily interactions between nursing staff and family members or patients are important, because every effort must be made to optimize the quality of interaction.

\section{ACKNOWLEDGEMENT}

Authors are much grateful to those patients and their relatives participating in the study. The author thanks the Post Graduate Research Fund (Grant Number: P0042-2012B), University of Malaya and participants.

\section{CONFLICT OF INTEREST}

The author declare no conflict of interest. 


\section{ABBREVIATIONS USED}

(FS-ICU): The Family Satisfaction-Intensive Care Unit; (QOC): Quality of Communication; SPSS: Statistical Package for Social Sciences.

\section{ABOUT AUTHOR}

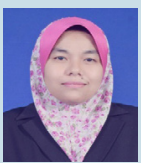

Hamidah Othman, obtained her Bachelor of Nursing Science in 2008 and Master of Nursing in 2013 from the University of Malaya. Her interest was a critical care in nursing and psychological need towards family members with patients' admit to the Intensive Care Unit, End of Life care and research in relation to the evidence based practice in nursing. She is currently working as Head and Lecturer at School of Nursing Science, Faculty of Medicine, University of Sultan Zainal Abidin, Kuala Terengganu, Malaysia.

\section{REFERENCES}

1. Hickman RL Jr, Douglas SL. Impact of chronic critical illness on the psychological outcomes of family members. AACN Adv Crit Care. 2010;21(1):80-91.

2. Sharma U, Bajaj L, Kaushal RK. Care of the Caregivers of the Patients Admitted in ICU. Available from:https://www.academia.edu/10383489/Care_of_the_Caregivers_of_the_Patients_Admitted_in_ICU [Accessed on 17-12-2015]

3. Sheaffer $\mathrm{H}$. The Met and Unmet Needs of Families of Patients in the ICU and Implications for Social Work Practice. Doctorate in Social Work (DSW) Dissertations. Paper 2. University of Pennsylvania, USA. 2010. Available from: http:// repository.upenn.edu/cgi/viewcontent.cgi?article $=1003 \&$ context=edissertatio ns_sp2 [Accessed on 17-12-2015]

4. Ely EW, Shintani A, Truman B, Speroff T, Gordon SM, Harrell FE Jr. Delirium as a predictor of mortality in mechanically ventilated patients in the intensive care unit. JAMA. 2004;291(14):1753-62.

5. Tate JA, Dabbs AD, Hoffman L, Milbrandt E, Happ MB. Anxiety and Agitation in Mechanically Ventilated Patients. Qual Health Res. 2012;22(2):157-73.

6. Gay EB, Weiss SP, Nelson JE. Integrating palliative care with intensive care for critically ill patients with lung cancer. Ann Intensive Care. 2012;2(1):3.

7. Russ AJ, Kaufman SR. Family perceptions of prognosis, silence and the "suddenness" of death. Cult Med Psychiatry. 2005;29(1):103-23.

8. Atkinson D. Nursing Observation and Assessment of Patients in the Acute Medical Unit. Professional Doctorate Thesis. School of Nursing, Midwifery \& Social Work College of Health \& Social Care University of Salford, Salford, United Kingdom. 2013. Available from: http://usir.salford.ac.uk/29466/1/E Thesis_DA.pdf [Accessed on 17-12-2015]

9. Cooke M, Oliver D, Burns A. Quality Care For Older People With Urgent \& Emergency Care Needs. 2012. Available from: http://www.bgs.org.uk/campaigns/silverb/silver_book_complete.pdf [Accessed on 17-12-2015]

10. Johnson JO, Sulmasy DP, Nolan MT. Patients' Experiences of Being a Burden on Family in Terminal Illness. J Hosp Palliat Nurs. 2007;9(5):264-9.

11. Reir DA. The missing voice of the critically ill: a medical sociologist's first-person account. Sociology of Health and Illness. 2001;22(1):68-93.

12. Davidson JE. Helping Families Adapt to Critical IIIness Family-Centered Care: Meeting the Needs of Patients' Families and Helping Families Adapt to Critical Illness. Crit Care Nurse. 2009;29(3):28-34.

13. Kinrade T, Jackson AC, Tomnay JE. The psychosocial needs of families during critical illness: comparison of nurses' and family members' perspectives. Australian Journal of Advanced Nursing. 2009;27(issue missing ??):82-8.

14. Loghmani L, Borhani F, Abbaszadeh A. Factors Affecting the Nurse-Patients' Family Communication in Intensive Care Unit of Kerman: a Qualitative Study. J Caring Sci. 2014;3(1):67-82.

15. Bizek KS. The Patient's Experience With Critical IIIness. Chapter 2. Available from: http://ferronfred.eu/onewebmedia/The\%20Patient\%E2\% $80 \% 99$ s\%20 Experience\%20With\%20Critical\%20IIIness.pdf [Accessed on 17-12-2015]

16. Kinrade T, Jackson AC, Tomnay JE. Social workers' perspectives on the psychosocial needs of families during critical illness. Soc Work Health Care. 2011;50(9):661-81.

17. Maxwell KE, Stuenkel D, Saylor C. Needs of family members of critically ill patients: A comparison of nurse and family perceptions. Heart Lung. 2007;36(5):367-76

18. Pfeiffer WJ. Conditions That Hinder Effective Communication. 1998. Available from: http://home.snu.edu/ jsmith/library/body/v06.pdf [Accessed on 18-12-2015]

19. Staggers N, Weir C, Phansalkar S. Patient Safety and Health Information Technology: Role of the Electronic Health Record. In: Hughes RG, editor. Patient Safety and Quality: An Evidence-Based Handbook for Nurses. Rockville (MD): Agency for Healthcare Research and Quality (US); 2008 Apr. Chapter 47. Available from: http://www.ncbi.nlm.nih.gov/books/NBK2644/ [Accessed on 18-12-2015]

20. Davidson JE, Powers K, Hedayat KM, Tieszen M, Kon AA, Shepard E et al. Clinical practice guidelines for support of the family in the patient-centered intensive care unit: American College of Critical Care Medicine Task Force 2004-2005.
Crit Care Med. 2007;35(2):605-22

21. Institute of Medicine (US) Committee on the Health Professions Education Summit; Greiner AC Knebel E, editors Health Professions Education: A Bridge to Quality. Washington (DC): National Academies Press (US); 2003. Chapter 3, The Core Competencies Needed for Health Care Professionals. Available from: http://www.ncbi.nlm.nih.gov/books/NBK221519/ [Accessed on 18-12-2015]

22. Azoulay E, Chaize M, Kentish-Barnes N. Involvement of ICU families in decisions: fine-tuning the partnership. Ann Intensive Care. 2014;4:37.

23. Bennun I. Intensive Care Units: A Systemic Perspectives. Journal of Family Therapy. 1999;21:96-112.

24. Stone PW, Hughes R, Dailey M. Creating a Safe and High-Quality Health Care Environment. In: Hughes RG, editor. Patient Safety and Quality: An EvidenceBased Handbook for Nurses. Rockville (MD): Agency for Healthcare Research and Quality (US); 2008 Apr. Chapter 21. Available from: http://www.ncbi.nlm. nih.gov/books/NBK2634/ [Accessed on 18-12-2015]

25. Clark PA. Intensive Care Patients' Evaluations of the Informed Consent Process. Dimensions of Critical Care Nursing. 2007;26(5):207-26.

26. Dodek PM, Heyland DK, Rocker GM, Cook DJ. Translating family satisfaction data into quality improvement. Crit Care Med. 2004;32(9):1922-27.

27. Dingley C, Daugherty K, Derieg MK, Persing R. Improving Patient Safety Through Provider Communication Strategy Enhancements. In: Henriksen K, Battles JB, Keyes MA, et al., Editors. Advances in Patient Safety: New Directions and Alternative Approaches (Vol. 3): Performance and Tools). Rockville (MD): Agency for Healthcare Research and Quality (US); 2008 Aug. Available from: http://www. ncbi.nlm.nih.gov/books/NBK43663/ [Accessed on 18-12-2015]

28. Wolf ZR, Hughes RG. Error Reporting and Disclosure. In: Hughes RG, editor Patient Safety and Quality: An Evidence-Based Handbook for Nurses. Rockville (MD): Agency for Healthcare Research and Quality (US); 2008 Apr. Chapter 35. Available from: http://www.ncbi.nlm.nih.gov/books/NBK2652/ [Accessed on 18-12-2015]

29. Sydnor ERM, PerlTM. Hospital Epidemiology and Infection Control in Acute-Care Settings. Clin Microbiol Rev. 2011;24(1):141-73.

30. Azoulay E, Pochard F, Kentish-Barnes N, Chevret S, Aboab J, Adrie C et al, FAMIREA Study Group. Risk of post-traumatic stress symptoms in family members of intensive care unit patients. Am J Respir Crit Care Med. 2005; 171(9):987-94

31. Medland JJ, Ferrans CE. Effectiveness of a structured communication program for family members of patients in an ICU. Am J Crit Care. 1998;7(1):24-9.

32. Heyland DK. Family Satisfaction with Care in the Intensive Care Unit@ (FS-ICU 24) version 11. Canada: Canadian Researchers at the End of Life Network (CARENET). 2006. Available from: https://www.qualitymeasures.ahrq gov/popups/printView.aspx?id=27592 [Accessed on 18-12-2015]

33. Stricker KH, Kimberger O, Schmidlin K, Zwahlen M, Mohr U, Rothen HU. Family satisfaction in intensive care unit: what makes the difference? Intensive Care Med. 2009;35(12):2051-9.

34. Heyland DK, Rocker GM, Dodek PM, Kutsogiannis DJ, Konopad E, Cook DJ et al. Family satisfaction with care in the intensive care unit: Results of a multiple center study. Crit Care Med. 2002;30(7):1413-18.

35. Heyland DK, Cook DJ, Rocker GM, Dodek PM, Kutsogiannis DJ, Peters S et al. Decision-making in the ICU: perspectives of the substitute decision-maker. Intensive Care Med. 2003;29(1):75-82

36. Badger JM. Factors that enable or complicate end of life care transitions in critical care. Am J Crit Care. 2005;14(6):513-22

37. Verhaeghe S, Defloor T, Van Zuuren F, Duijnstee M, Grypdonck M. The needs and experiences of family members of adult patients in an intensive care unit: A review of the literature. J Clinic Nurs. 2005;14(4):501-09.

38. Paul F, Hendry C, Cabrelli L. Meeting patient and relatives' information needs upon transfer from an intensive care unit: the development and evaluation of an information booklet. J Clin Nurs. 2004:13(3):396-405. 